\title{
A Coisa Julgada em Direito Tributário*.
}

\author{
Ruy Barbosa Nogueira \\ Catedrático de Direito Tributário da Faculdade de \\ Direito da Universidade de São Paulo.
}

\begin{abstract}
SUMÁRIO. A relação jurídico-tributária como objeto da lide. Impostos periódico's e instantâneos. ICM, ISS e "numerus clausus". Distingão entre provimento "normartivo" e "preventivo" ou repressivo", em tema de mandado de segurança. A coisa julgada no executivo fiscal e no mandado de segurança. Vinculação dos tribunais. Segurança e paz jurídicas. Confiança dos jurisdicionados. Coisa julgada e ato continuado. Sistematização. Informatica Jurídica. Computador. $A$ exigência de imposto sabidamente indevido e o Código Penal. Concurso formal em relação à austeridade impetrada.
\end{abstract}

\section{O fato objeto deste estudo.}

Uma determinada empresa, na conformidade de um dos seus objetivos sociais, vinha e vem prestando os serviços de engenharia consistentes no fornecimento de massa úmida de concreto, dosada, certificada e profissionalmente garantida, especificamente para cada respectiva construção adquirente desse serviço.

*. Adaptação de parecer para o sistema de estudo por meio de "casos e problemas".

Para motivação e auto-realização dos alunos, inicialmente só se lhes distribui a primeira parte ( $O$ fato objeto deste estudo).

Somente depois de os alunos haverem pesquisado, debatido o caso, estudado e apresentado seus próprios trabalhos é que se lhes distribui a segunda parte (Problemática, estudo e conclusões do caso exposto), para que possam confrontar sua solução com a elaborada pelo professor. 
De ocordo com o sistema jurídico tributário vem pagando, integralmente, o imposto municipal sobre serviços. Aliás, a exposição e exatidão dessa forma de proceder da consulente foi confirmada por parecer de $12 / 2 / 69$, de autoria do Prof. Ruy Barbosa Nogueira e publicado no livro Direito Tributário - 1. ${ }^{\mathrm{a}}$ Coletânea, editora Bushatsky, S. Paulo, 1969, pp. 133/147.

Conforme decisões judiciais, tanto em mandado de segurança como em ação executiva fiscal, já passadas em julgado, foi acolhido esse parecer e ficou decidido o mérito, no sentido de que sobre o exercício dessa atividade da consulente é devido o imposto sobre serviços (ISs), de competência privativa do Município e que sobre a mesma atividade não incide, nem poderia incidir, o imposto estadual sobre operações relativas à circulação de mercadorias (ICM), posto que a partilha tributária não admite essa invasão da competência impositiva exclusiva do Município e garante ao contribuinte não ser bitributado.

Acontece que a fiscalização do Estado lavrou contra a ora consulente grande quantidade de autos de infração, na tentativa de lhe cobrar ICM e multas, pretensão essa julgada manifestamente ilegal, por ferir direito líquido e certo do contribuinte.

Sendo, tanto o Iss pago continuadamente pela consulente, como o ICM continuada e ilegalmente pretendido pelo Fisco estadual impostos continuativos ou não lançados, uma vez resolvida precisamente essa relação jurídica tributária, tanto em tema de mandado de segurança, como em ação executiva fiscal, são tormulados os seguintes quesitos, em face das decisões definitivas anexas:

1.') Qual a distinção entre mandado de segurança normativo e preventivo ou repressivo, em relação aos efeitos temporais da ordem concedida?

2. ) A decisão de mérito, proferida "in casu", no mandado de segurança concedido definitivamente à ora consulente, é oponível à autoridade coatora, como ordem para 
cessar ou não repetir essa mesma coação, ou teria a vítima da coação de assoberbar o Poder Judiciário com a impetração de mandados de segurança em relação a cada um dos inumeráveis atos praticados e continuados, de saída dos caminhões ou de emissão de cada nota fiscal?

$\left.3^{\circ}\right)$ A decisão de mérito sobre a relação jurídico-tributária "in casu", no Mandado de Segurança, constitui "coisa julgada"?

$4^{\circ} .^{\circ}$ A decisão de mérito sobre a relação jurídico-tributária "in casu", na ação executiva fiscal, constitui "coisa julgada"?

5. ) Por se tratar de impostos não pode o contribuinte obter do Poder Judiciário a segurança e tranquilidade quanto a uma determinada relação jurídico-tributária contínua?

Problemática, estudo e conclusões do caso exposto.

I. As decisões alcançadas pela consulente, definitivamente, em tema de mandado de segurança e em ação executiva fiscal, ambas sobre a mesma relação jurídico-tributária, demonstram à saciedade que, reiteradamente, o assunto ficou soberanamente encerrado com os efeitos da "coisa julgada".

Nos termos deste instituto a ora consulente encontra-se hoje investida num dos direitos e garantias individuais que a Constituição Federal prevê no art. $^{\circ} 153$, $\S 3 .^{\circ}$, pelo qual estabelece a autovinculaçâo do Estado no interesse da segurança jurídica, da paz jurídica e da confiança dos jurisdicionados, se não vejamos:

A relação jurídico-tributária como tema de mérito, tanto dos mandados de segurança concessivos, como da ação executiva fiscal e a coisa julgada. 
II. Por simples desconhecimento do Sistema Jurídico Tributário Nacional, pretendeu a Fiscalização da Fazenda do Estado de São Paulo coagir a ora consulente a pagar o ICM, iniciando a coação pela lavratura de auto de infração que é peça acusatória de ocorrência de fato típico ou fato gerador, categoria esta plenamente juridicizada já no plano da legislação para-constitucional ("loi quadre", "Rahmengesetz") ou pela lei organica da tributação, que é o Código Tributário Nacional. nestes termos:

"Art. 114 - Fato gerador da obrigação principal é a situação definida em lei como necessária e suficiente à sua ocorrência".

“Art.97 - Somente a lei pode estabelecer:

I - a instituição de tributos. .

III - a definição do fato gerador da obrigação principal. .

IV - a fixação da alíquota do tributo e da sua base de cálculo. .

V - a cominação de penalidades. "

III. Portanto, o cTN com o caráter de legislação complementar da Constituição ( art. $^{\circ} 18 \S 10^{\circ}$ ) exige a configuração absoluta e integral da hipotização de incidência nos textos legais como pre-requisito da incidência, colocando no art. $^{\circ} 114$ até as condições lógicas da implicação dupla (necessária e suficiente), ou seja, de eqüivalência.

IV Como ensina o eminente catedrático de Heidelberger, Ulnich Klug, em sua famosa Juristische Logik, ao tratar precisamente das condições necessária, suficiente $\mathrm{e}$ também da necessária e suficiente:

"as três classes indicadas de condições ou pressupostos correspondem respectivamente à impli- 
cação extensiva e a de eqüivalência (implicação dupla).

Especialmente a condição suficiente corresponde à consequência da implicação extensiva; a condição necessária corresponde à consequência da implicação intensiva; a condição necessária e suficiente a uma das premissas da relação de equivalência".

"No caso da eqüivalência tanto o antecedente como o consequente podem chamar-se implicantes. Isto decorre de que, reunidas a necessária e suficiente, a eqüivalência constitui uma implicação dupla ${ }^{1}$

V. Por conseguinte, em nosso sistema jurídico-tributário as condições "necessária e suficiente" para ser exigido imposto ou multa, preliminarmente requerem a existência de lei com prefiguração de todos os requisitos do art. $^{\circ} 97$, ou seja, tipificação legal plena, também chamada de tipologia taxativa" ou ainda "tipicidade fechada".

VI. Sendo a obrigação fiscal protDtipo da obrigação "ex lege", o seu "prius" é, pois, a hipótese de incidência ou previsão em lei.

Logo, no caso nada mais adequado para contestar a falsa pretensão do que o mandado de segurança, com a simples demonstração da inexistência de legalidade para essa exigência, pois não há no caso nenhuma "quaestio facti" 2 .

Raramente se pode encontrar, em tema de impostos, questão de direito tão cristalina com previsão de "direito líquido e certo" do contribuinte. A Constituição Federal

1. Juristische logik, Dritte, erweiterte und verandert Alflage, Springer-Verlag, Berlin-Heidelberg-New York, 1966, pgs. 41/42.

2. Confronte Da Coisa Julgada em Mandado de Segurança, IvAN ORDINE RIGHT, R.T. 427/21. 
prevê no art. 24, II, a competência privativa do Município sobre os serviços "definidos em lei complementar" e por sua vez a legislação complementar colocou em "numerus clausus" esse serviço como da competência privativa do Município, como se vê do Decreto-lei n. ${ }^{\circ} 406$, $^{2}$ rt. $^{\circ} 8 .^{\circ}$ n. ${ }^{\circ} 19$ da Lista ${ }^{3}$.

Não só não existe o "prius" ou hipotetização legal em favor do Estado, mas antes, proibição ao Estado de arrogarse titular dessa hipótese de incidência.

Portanto a questão é apenas de direito ou mesmo, de simples jus in civitate positum.

VII. Acontece que a ora consulente, além de ter a seu favor já essa clareza, essa fixidez por "numerus clausus" ou Lista, em disposições literais da legislação complementar a seu favor, invocou a proteção do Poder Judiciário e a obteve reiterada e conclusivamente.

Com efeito:

1. $\left.{ }^{\circ}\right)$ Como se vê do agravo de petição $\mathrm{n}^{\circ}$ 135.493, em Mandado de Segurança, chegado até à Suprema Corte pelo Agravo de Instrumento $n .^{\circ} 52.287$, esta confirmou seu ganho de causa, no sentido de que sobre a sua questionada atividade só é devido o imposto municipal (Iss) que vem pagando e vedado o ICM.

Quem quer que examine nos autos as decisões desde à primeira até à última instância, verifica que foi invocada e apreciada toda a legislação pertinente, até a atualmente vigente. A certidão de transito em julgado consta dos autos às fls. 216. Não pode haver dúvida de que esse julgamento formal e materialmente passou a constituir "coisa julgada", nos precisos termos do art. ${ }^{\circ} 287$ do G.P.C.

3. Sobre "numerus clausus", "exclusivismo", condições "necessária e suficiente" no Direito Tributário, confronte-se ainda a notável e recente obra do Prof. Alberto Pinheiro Xavikr, Conceito e Natureza do Acto Tributário, Coimbra, 1972, pgs. 322 a 328. 
2..$^{\circ}$ Também na Ação Executiva Fiscal, Agravo de Petição $n .^{\circ} 173.535$, a mesma relação jurídico tributária foi integralmente questionada e arquivado o Agravo de Instrumento interposto pela Fazenda por incabível o Recurso Extraordinário e nos termos do mesmo art. $^{\circ} 287$ produzida $^{2}$ a "coisa julgada".

3. ) Novamente, em tema de Mandado de Segurança, por unanimidade, como se vê do Agravo de Petição n. ${ }^{\circ}$ 192.118, foi concessiva a ordem no mérito e a contribuinte opos e está pedindo o reconhecimento da coisa julgada que obteve.

VIII. Ara, no caso "sub judice" não se trata, nem sequer, de imposto de lançamento anual (em que já se levantou o problema, aliás mesmo aí impertinente, da anualidade do orçamento), mas sim de imposto não lançado, de imposto instantâneo ou continuativo.

Mesmo para os impostos periódicos ou de lançamento anual, com absoluta procedência e antevisão, já esclarecera no S.T.F. o eminente Ministro Castro Nunes:

"A coisa julgada existe em qualquer processo contencioso, seja de que natureza for, ordinário, sumário, ou especial, sem possivel exclusão do executivo, desde que se decida da relação jurídica por contestação entre as partes. Só não induzem a coisa julgada os processo mencionados na lei processual, entre os quais não estão os executivos, fiscais ou não" (R.D.A. vol. II, Fasc. II, p. 554).

Por isso mesmo o Tribunal de Apelação de São Paulo, já em 1944, deixara decidido:

"como tem estabelecido o Supremo Tribunal Federal, designadamente em matéria de cobrança de impostos, por identidade de coisa deve entenderse, não o mesmo corpo ou o mesmo objeto, senão 
a mesma controversia ou a mesma relação de direito já resolvidas".

(Agravo de Petição n. ${ }^{\circ}$ 22.414, R.D.A. vol. II, Fasc. II, p. 589).

IX. Uma vez decidida reiterada e definitivamente a questão, não vemos como no caso não se reconheçam os ef eitos da coisa julgada, quando o c.P.c. estabelece:

"Art. ${ }^{\circ} 287$ - A sentença que decidiu total ou parcialmente a lide terá força de lei nos limites das questões decididas.

Parágrafo único - Considerar-se-ão decididas as questões que constituam premissa necessária da conclusão.

X. A lide consistiu precisamente na discussão da existência ou inexistência da "relação jurídico-tributária", isto é, se uma determinada, efetiva e continuada atividade da empresa Concretex está prevista na legislação como sujeita ao I.c.M. O Poder Judiciário, em tema de Mandando de Segurança decidiu que não existe na legislação sequer essa hipótese de incidência. Mais ainda, que não só não existe relação jurídico-tributária em favor do Estado, mas existe essa hipótese de incidência ou relação jurídico-tributária outorgada pela Constituição e pela legislação para-constitucional, privativa ou exclusivamente, ao Município, o que ainda significa exclusão do Estado do próprio poder de tributar essa atividade, pois se o fizer estará praticando conflito ou invasão de competência privativa do Município que a já exerceu e está, legitimamente recebendo, com exclusividade, o Iss que a contribuinte Concretex está, efetiva e continuadamente pagando.

XI. O fulcro da pergunta do $10^{\circ}$ quesito é saber se a coisa julgada neste tema de mandado de segurança não poderia levar à suposição errônea de que se teria obtido uma ordem de mandado de segurança normativa. 
Como muito bem esclarece Hely Lopes Meirelles,

"segurança normativa seria a que estabelecesse regra geral de conduta para casos futuros, indeterminados" 4 .

Precisamente em questão de IcM, o jovem e talentoso Promtor Público Ronaldo Porto Macedo, já esclareceu, com precisão, em parecer publicado na Revista "Justitia", vol. 76, p. 148:

"trata-se de segurança preventiva e não normativa, pois esta ocorreria se a sentença estabelecesse um regramento genérico e abstrato, aproveitando a todos que estivessem em situação igual à da impetrante, independentemente da existência de uma determinada situação concreta, conflitante e permanente, envolvendo sujeitos perfeitamente definidos, que divergem, quanto ao entendimento e aplicação concreta de um dispositivo legal".

Ora, a ordem obtida pela consulente foi "in casu" entre determinadas partes, tendo como objeto esclarecer uma deminada "relação jurídico-tributária", em face do direito positivo vigente.

XII. Como já ensinava S. Tomás de AQuino no livro das Leis,

“os legisladores julgam em geral e para o futuro; ao passo que os homens, que presidem ao juizo, julgam do presente" (legislatores judicant in universali et de futuris; sed hominis judiciis praesidentis judicant de praesentibus) ${ }^{5}$.

4. Mandado de Segurança e Ação Popular, Editora R.T., 2. ${ }^{\text {a }}$ edição, São Paulo, 1969, pg. 45.

5. Suma Teológica, tradução do Prof. Alexandre Correia, Editora Odeon, São Paulo, 1936, pg. 76. 
XIII. A coisa julgada obtida "in casu” é, com precisão, um exemplo feliz para esclarecer essa questão em face do ato continuado, frequentemente existente no campo dos chamados impostos indiretos, não lançados, instantâneos, de autolançamento ou ainda continuativos, como o é, tipicamente, o IGM ${ }^{6}$.

XIV. É interessante observar que a mesma Fazenda do Estado de São Paulo, em causa que patrocinamos como advogado do contribuinte, chegou a levantar idêntica argüição, logrando, de início, cassação da ordem, a que contrapuzemos a Correição Parcial n. ${ }^{\circ} 314 / 68$ na $1 .^{a}$ Vara da Fazenda Estadual. O ilustre Magistrado reconsiderou seu ato e obtivemos a confirmação do Egrégio Tribunal de Alçada Civil e afinal a coisa julgada precisamente sobre o mesmo tema da relação jurídica do IGM como ato continuado $^{7}$.

Neste passo, são relevantes e aplicáveis como luva ao caso da ora consulente, os fundamentos da sentença reconsideranda, "mutatis mutandis" em todos os seus termos, que são os seguintes:

6. Elementarmente sabido que os impostos se dividem em diretos e indiretos, também chamados lançados e não lançados, ou ainda periódicos e instantâneos. Periódicos são aqueles cuja realização do "fato gerador" compreende um período, geralmente anual, como são exemplos o Imposto de Renda lançado, que toma todo o "ano-base"; ou o Imposto Predial que compreende todo um exercício.

O imposto não periódico, instantâneo ou continuativo, ao contrário, é aquele cujos exemplos típicos são o ICM e o ISS do caso da consulta, que são impostos não lançados ou de autolançamento, cujo "fato gerador" ocorre em cada momento, em cada operação realizada e por isso são continuativos.

7. Vide acórdão unânime nos autos da Correição Parcial n. ${ }^{\circ} 171.490$, Primeira Câmara do Tribunal de Alçada Civil, proferido em 21/3/72 Certidão do trânsito em julgado de 24/5/72.

Vide ainda confirmação da "coisa julgada" no tocante ao I.C.M. pelo acórdão também unânime nos Autos do Recurso "Ex officio" n. ${ }^{\circ}$ 189.373, Segunda Câmara do Primeiro Tribunal de Alçada Civil, prolatado em 4/4/1973. 
"Examinando melhor a pretensão do Frigorifico Anglo, requerente da presente Correição Parcial, reconheço a sua procedência.

Efetivamente, nos autos principais de Mandado de Segurança, o requerente pleiteou e obteve segurança definitiva para a exportação de carne congelada ou resfriada, sem a exigência de pagamento do I.C.M., não só para os embarques já programados, como também para as futuras saídas do referido produto, com destino ao exterior.

Ora, uma vez transitada em julgado a decisão onde, estreme de dúvidas, ficou reconhecido como industrializado o produto em questão e, como tal, imune à tributação do I.c.M., quando destinado à exportação, não pode pretender, agora, a Fazenda do Estado obstacular a execução do julgado.

Aliás, como muito bem observou o digno representante do Ministério Público, em seu judicioso parecer de fls. 31/33, o requerente, no caso, visa dar à r. sentença de fls. $54 / 57$ e ao v. acórdão de fls. 69, dos autos principais, a execução fiel e exata que compete às coisas julgadas, como o recomenda o art. $^{\circ} 891$ do c.P.c. e conclui:

“A Fazenda deverá, querendo, socorrer-se dos meios processuais próprios, para intentar a modificação do decidido (coisa julgada). Mas não pode restringi-lo nesta fase executória".

Por outro lado, no caso, não há como se falar em mandado de segurança normativo, pois o próprio Prof. Hely Lopes Meirelles, no trecho citado pela Fazenda do Estado, é precisamente a favor da medida preventiva concedida ao Frigorífico Anglo, ao esclarecer: 
"A segurança normativa seria a que estabelecesse regra geral de conduta para casos futuros, indeterminados."

No caso, a segurança foi pedida e concedida específica e determinadamente para a exportação continuada, para o caso determinado do impetrante Frigorífico Anglo que o provou e requereu para, em relação a determinado imposto estadual e contra uma determinada interpretação errônea, de uma determinada autoridade coatora e a obteve com os efeitos da coisa passada em julgado, ou seja:

"para o fim de não ser obrigado a recolher o imposto sobre Circulação de Mercadorias ICM nas saídas, da carne congelada ou resfriada destinada ao exterior".

(Item IV “b” da petição inicial e fls. 32 do parecer da Promotoria).

Esse pedido foi ainda reiterado a fls. 46, quando tornou a pedir e obteve:

"a extensão dos efeitos da liminar concedida aos embarques cujas licenças estão anexas, bem como aos demais a serem efetuados, cujas licenças ainda não foram expedidas pelo órgão competente, afim de que a suplicante não sofra manifesto prejuízo".

Ora, o ato de exportação dessa sua mercadoria, pela própria impetrante, no cumprimento do contrato de compra e venda para o exterior é um verdadeiro procedimento, pois como ensina Emílio Betti “o procedimento consiste em vários atos jurídicos sucessivos visando à mesma finalidade, dos quais, todo ato que segue, pressupõe necessariamente o precedente, preparando e prenunciando o seguinte" (Teoria Generale del Negocio Giuridico, in Trattato di Diritto Civile Italiano, 
dirigido por Fillippo Vassali, vol. 15, tomo II) (7'). Mas precisamente, é um ato continuado e a própria legislação fiscal de nosso País, até mesmo para aplicação de multa considera e categoriza, juridicamente, o ato continuado como uma unidade ou sequência. Assim, o Decreto n. ${ }^{\circ}$ 61.514, de 12 de outubro de 1967, considerado o nosso estatuto fiscal mais completo em matéria de procedimento administrativo reza:

"Art. 151

$\S 2 .^{\circ}$ - As infrações continuadas. . estão sujeitas a uma pena única. $\quad " 8$ e o Código Penal, no art. $^{\circ} 51, \S 2 .^{\circ}$, também, para o mesmo efeito, caracteriza a unicidade do ato continuado. ${ }^{8}$,

Ora, para o caso do impetrante foi concedida a ordem de segurança preventiva contra a ameaça comprovada de que a autoridade coatora, por errônea interpretação estava impedindo o exercício do direito líquido e certo de o impetrante exportar a sua mercadoria debaixo da imunidade. Como é sabido, a imunidade é uma categoria muito mais ampla do que a simples isenção. A imunidade tributária é uma limitação constitucio-

7' Nota do autor deste trabalho: Em relação ao "Procedimento Administrativo" confronte-se o art. 142 do CNT. Quanto à figura do "Ato Continuado" no processo, veja-se in CARNELUTTI, Sistema del Diritto Processuale Civile, edição CEDAM, 1938, vol. II, pg. 94 letra "d" e a partir da pg. 109, n. 433, especificamente Atti Processuali Continuati.

8. Nota do autor deste trabalho: Observe-se que os citados arts. 151 e $\S 2 .^{\circ}$ estão em pleno vigor e até ressalvados expressamente pelo art. 269 do Decreto Federal $n .^{\circ} 70.162$, de $8 / 2 / 72$, pois pertencem ao Título IV (Das infrações e penalidades).

8'. Idem: em relação ao ato continuado no Direito Penal, veja-se a magnífica monogracia do Magistrado e Professor MANOEL PEDRO Pimentel, Do Crime Continuado, editado pela Revista dos Tribunais, S. Paulo, 968, "passim" e especialmente de pgs. 201 a 214 o título Crime continuado e coisa julgada. 
nal que exclui o próprio poder de tributar, isto é, quando o $\S 7 .^{\circ}$ do art. $^{\circ} 23$ da Constituição reza, imperativamente, que o Imposto sobre Circulação de Mercadorias "não incidirá sobre as operações que destinem ao exterior os produtos industrializados" criou uma imunidade também chamada de "não incidência qualificada". Retirou por aí dos Estados, a própria competência de tributar essas exportações por meio do I. C.M.

Finalmente, se prevalecesse a tese defendida pela Fazenda do Estado, não obstante a segurança obtida, o impetrante teria que se valer do remédio heróico toda vez que necessitasse exportar os produtos que industrializa, o que se me afigura absurdo, mesmo porque "isto importaria na criação de obstáculo intransponível para o exercício de sua atividade comercial", conforme bem salientou a r. decisão citada às fls. 10 .

Isto posto, julgando procedente a presente Correição Parcial, reconsidero o despacho de fls. 122, para determinar que a Fazenda do Estado, em obediência ao julgado, se abstenha da exigência do ICM nas exportações de carne congelada ou resfriada efetuadas pelo Frigorífico Anglo. Custas, na forma da lei. Int. São Paulo, 19 de novembro de 1971. Gabriel Cuba dos Santos. Juiz de Direito".

$\mathrm{XV}$. Eis aí, com clareza merediana, a diferença entre a natureza do mandado de segurança normativo (figura que legalmente não existe) e a natureza do provimento do mandado de segurança preventivo ou repressivo.

XVI. Às págs. 44 e 45 da já citada obra, Hely LOPES Meirelles esclarece, precisamente, esse ponto:

"O mandado de segurança admite decisão repressiva e preventiva $\left(\operatorname{art}^{\circ}{ }^{\circ} .^{\circ}\right)$. É repressiva 
quando visa a corrigir ilegalidade já consumada, é preventiva quando se destina a impedir o cometimento de ilegalidade iminente. Em ambos os casos é necessária a indicação do objeto e a comprovação da iminència da lesão a direito subjetivo do impetrante".

"Não se confunda - como frequentemente se confunde - segurança preventiva com segurança normativa. $\mathrm{O}$ nosso sistema judiciário admite aquela e rejeita esta. Segurança preventiva é a que se concede para impedir a consumação de uma ameaça a direito individual em determinado caso; segurança normativa seria a que estabelecesse regra geral de conduta para casos futuros, indeterminados" (grifos do autor e da transcrição).

XVII. A Concretex impetrou e obteve, com o caráter definitivo de "coisa julgada" a solução do objeto de uma sua determinada atividade continuada, em relação a dois impostos continuativos, em confronto com a exigência continuada do Fisco estadual, em razão de uma determinada e errônea interpretação continuada de determinada legislação e o Poder Judiciário solucionou a controvérsia, objeto da lide.

XVIII. Esta solução, como por tantos anos nos ensinou na Faculdade o Mestre Enrico Tullio Liebman e o diz em sua clássica obra "Eficácia e Autoridade da Sentença" traduzida por Buzaid e Aires, tornou-se "coisa julgada formal e substancial" (p.56), nos "limites objetivos e subjetivos" (p. 51) ${ }^{9}$.

XIX. Vejam-se ainda os comentários de Liebman a acórdão de nosso Supremo Tribunal Federal, precisamente

9. Edição Revista Forense, Rio, 1945. 
sobre a coisa julgada em matéria fiscal, onde conclui, com sua lapidar clareza:

"As regras relativas à coisa julgada recebem, pois, integral aplicação em matéria fiscal, e não há razão para admitir-se desviações ou restrições, devidas à natureza especial da função desenvolvida pelo Estado, quando cobra os impostos para satisfazer as necessidades de ordem geral. Ainda quando desenvolve essa função, o Estado está submetido ao direito objetivo, à jurisdição e à coisa julgada" 10 .

Também Allorio, outro renomado processualista, em sua obra Diritto Processaule Tributario, tratando da "cosa giudicata tributaria", à p. 259, esclarece igualmente:

"La decisione avente forza di cosa giudicata, anche nel processo tributario, produce dunque quei ridigi effetti che le sono propri nel diritto processuale comune" ${ }^{11}$.

XX. Nas obras mais recentes e mais notáveis da literatura tributária mundial, tais como no Handwörterbuch des Steurrechts und der Steuerwissenschaften que, pelo seu conteúdo, traduzimos por Dicionário Enciclopédico do Direito Tributário e da Ciências Fiscais, basta consultar os verbetes

Rechtskraft - coisa julgada

Bindungsproblem - problema da vinculação

Streitgegenstand - objeto do litígio

Urteil - sentença ${ }^{12}$

10. Revista de Direito Administrativo, vol. II, Fasc. II, outubro de 1945, pg. 565 .

11. Edição Dott. A. Giuffré, Milano, 1942.

12. Edição C. H. Beck'sche Verlagsbuchhandlung, München e Wissenschaftlichen Instituts der Steverbevollmäctigten GMBH Bonn, 1972 . 
Na obra Steuerrecht (Direito do Imposto) do catedrático Wilhelm Kruse, p. 318 e segs., Wirkungen des Urteiles (Efeitos da sentença) ${ }^{13}$, e por todos esses elementos ver-se como liebman e Allorio foram exatos em seus magistérios sobre a "coisa julgada", em matéria tributária.

Sendo o instituto da "coisa julgada" de direito público e mais especificamente de direito constitucional, existe até "a fortiori" maior necessidade e utilidade de sua aplicação no campo da disciplina jurídica do fenômeno fiscal, porque a tributação é fenômeno sócio-econômico-financeiro em massa: portanto a "coisa julgada" é ainda mais necessária para a maior segurança do povo contribuinte, para a paz entre o Estado-Fisco e o Cidadão-Contribuinte e para a confiança dos contribuintes no Poder Judiciário, como jurisdicionados.

XXI. Mas não é só.

Imagine-se ainda do ponto de vista prático, em um país como o Brasil, onde os maiores impostos são os continuativos ou de auto lançamento (IPI, ICM, IMPostos do comércio exterior, parte do I.R., do Iss etc.), se cada contribuinte tivesse que impetrar mandado de segurança, propor ação ou ser demandado em cada ato a ser praticado, ou continuado, como ficariam os tribunais sufocados em atos repetitivos ou de rotina ${ }^{14}$

Ao revérso, a característica fundamental de toda a filosofia ocidental, aproveitada agora como possibilidade da

13. 2., vollig überabeitete Auflage, C.H. Beck'sche Verlagsbuchandlung, München, 1969. Na $3 .^{a}$ edição, 1973, vide mais desenvolvida a questão, a partir da pg. 358 .

Acrescente-se Bestandskraft und Rechtskraft, pgs. 302-303 do livro Lehrbuch des Allgemeinen Steuerrechts, de HEINz PAULICK, 2.a edição, Carl Heymanns Verlag KG, Köln-Berlin-Bonn-München, 1972.

14. Veja-se no Dicionário do Direito Tributário já citado, vol. I, pg. 96, a importância da "praticabilidade" (Diepraktikabilität) no campo tributário, em razão do fenômeno em massa, dos casos (Phänomen der Massenhaftigkeit) que as autoridades têm que resolver, como nesse mesmo sentido os acórdãos da Corte Tributária Federal (BFH), aí citados. 
Informática Jurídica na era do computador, é precisamente a da procura da sistematização, da unificação de conceitos universais e válidos para solução da gigantesca problemática que a vida atual apresenta, cada vez mais, com a feição de volume em massa.

A idéia criadora de Wiener veio possibilitar o uso da automação, especialmente para aliviar o trabalho intelectivos, dos atos repetitivos ${ }^{14}$ ".

Se já havia no plano intelectivo algo semelhante aos efeitos da automação eletrônica que o grande sábio matemático veio doar à humanidade, parace-nos que é o do instituto da "coisa julgada", antecipadamente criado e aplicado pelo gênio dos juristas que, na verdade, já haviam construido um verdadeiro "computador" invisível, não eletrônico, mas superior, porque no cérebro humano e portanto "cognoscente" ou "racional".

Realmente o instituto da "coisa julgada" é uma solução conceitual e sistematizada que reduzindo-se à unicidade, obsta os atos repetitivos ilegítimos, dando ampla e uniforme cobertura ou eficácia ao regime do direito.

XXII. Produzida adequadamente a "coisa julgada" é com ela alimentado o computador eletrônico, não há dúvida que a conquista da ciência interdisciplinar que o gênio da Cibernética nos legou, virá aumentar a efetividade da segurança jurídica, desde que os juristas permaneçam como sentinelas da correta produção e aplicação do direito.

XXIII. O que nos parece inconcebível hoje, mais do que nunca, é que no campo tributário do lançamento, onde

14ª Cfr. Niorbet Wiener, Cibernética e Sociedade, Editora Cultrix, S. Paulo, passim.

Mario G. Losano, Sistema e Strutura nel Diritto, G. Giappichelli-Editore-Torino, 1968, vol. I, e especialmente Corso di Informática Giuridica, Cuem, Milano, 1971, ainda Lições de Informática Jurídica, curso realizado no Departamento de Direito Econômico-Financeiro da Faculdade de Direito da USP, professor responsável RUY BARBosA NoGUeIRA, Editora Resenha Tributária, 1974, pgs. 1 a 5. 
a própria administração emprega o computador (SERPRo PRODESP - PRODAM), para lançar e exigir os impostos e o próprio Judiciário paulista ensaia a computação nas sentenças repetitivas, se possa deparar, no caso dos impostos continuativos, uma tal obstinação contra o conceito milenar da sistematização e da aplicação do genial instituto da "coisa julgada". No dizer do Handwörterbuch des Steuerrechts ela é apenas uma “autovinculação dos próprios tribunais, pela qual a segurança jurídica, a paz jurídica e a proteção da confiança dos jurisdicionados exigem que os tribunais mantenham suas decisões conclusivas" 15 .

XXIV. Portanto, a solução da relação jurídico-tributária de que dá notícia a consulente é definitiva e sem sombra de dúvida oponível à Fazenda do Estado de São Paulo. Esta não só não pode renovar a coação, mas estando, como está, integralmente ciente de que essa cobrança é manifestamente ilegal, por decisão definitiva do Poder Judiciário, no interesse da sociedade e proteção de seus próprios funcionários deve "ex offício" desistir de toda tentativa no sentido dessa exigência.

Este dever da Fazenda seria mesmo homenagem ao art. ${ }^{\circ}$ 316 do Código Penal (reproduzido no futuro Código), que tipifica como delito o "excesso de exação", assim considerado:

"Art. ${ }^{\circ} 316-\ldots$

$\S 10^{\circ}$ - Se o funcionário exige imposto, taxa ou emolumento que sabe indevido, ou, quando devido, emprega na cobrança meio vexatória ou gravoso, que a lei não autoriza"

15. Selbstbindung des BFH: - Rechtssicherheit, Rechtsfrieden und Vertrauensschutz (Treu und Glauben) erfordern es, dass die Revisionsinstanz bei erneuter Entscheidung über dieselbe Sache nach einer Zurückverweisung ihre ursprünglich geäusserte Rechtsauffassung beibehält. (Obra citada, item 8 da pg. 205). 
Não há dúvida que, para a ocorrência dessa figura, é pré-requisito o dolo, que não se presume. Entretanto é instrutiva e cautelar a leitura dos doutos em Direito Penal. Comentando o dispositivo acima transcrito, ensina o Catedrático Magalhães Drummond:

"Na hipótese da simples exigência do indébito, o dolo estará na consciência disto - na consciência de não ser devida legalmente a taxa, imposto, ou emolumento, e, entretanto, exigí-lo, pondo assim em ação uma vontade poluida do ponto de vista moral e criminosa, do prisma legal.

$\mathrm{Na}$ hipótese de cobrança vexatória ou gravosa da contribuição devida, já o dolo consiste na consciência da of ensa ao direito que o contribuinte como pessoa humana tem de ser respeitado no seu pundonor e no seu patrimônio. Esse dolo se presume do fato mesmo concretizador da ofensa, porque se pressupõe no funcionário o conhecimento da extensão dos seus deveres e das limitações postas pela lei ao seu exercício. Tanto mais quanto o excesso constitue crime do Código Penal, cuja ignorância não se compadeceria com a qualidade de funcionário, ademais da sua geral inalegabilidade. Existindo precisamente para por em ação a lei, o funcionário sabe, por presunção legal, o que lhe cumpre fazer, e, se, em assunto tão importante, age contra a lei, é, de certo, com a consciência da ilegalidade da sua conduta.

O crime nesta hipótese se perfaz mediante procedimento vexatório ou gravoso. Gravoso compreenderia de modo geral também o vexatório, pois gravoso é o que traz malefício, agravo, prejuizo, e nada mais gravoso do que o prejuízo moral. Mas fêz bem o legislador em discriminar, porque, assim, pôs bem em realce o propósito do respeito à pessoa humana, que êle não quer dimi- 
nuída, humilhada, aviltada, envergonhada pelo representante da administração pública, a qual existe principalmente para realizar a conciliação do interesse coletivo, que tem por órgão o Estado, com o direito do indivíduo - interesse e direito que são medida um do outro, no ajustamento legal" 16 .

Convém esclarecer que a falta de providência da autoridade coatora, a que no caso, cabe expedir instruções fiscais em contramarcha, aos funcionários encarregados da fiscalização, autuação e cobrança, para não deixá-los no risco de incidirem no excesso de exação, a falta de cumprimento da ordem judicial por parte da autoridade coatora incidirá também no mesmo Código Penal, que prevê o crime de desobediência:

" $O$ não atendimento do mandado judicial, caracteriza o crime de desobediência a ordem legal (Código Penal, art. 330) e por ele responde o impetrado renitente, sujeitando-se até mesmo à prisão em flagrante, dada a natureza permanente do delito" (Hely Lopes Meirelles, op. cit., p. 43).

Em relação, pois, à autoridade coatora impetrada poperá, no caso de se efetivar nova coação, ocorrer até o "concurso formal" dos crimes de excesso de exação previsto no art. $316, \S 2 .^{\circ}$ e o de “desobediência" previsto no art. 330, de conformidade com o art. 51, $\S 1 .^{\circ}$ do mesmo Código Penal que disciplina o concurso formal de crimes.

\section{Conclusões.}

Em face de todo o exposto, assim respondemos aos quesitos formulados na consulta:

16. Comentários ao Código Penal, J. de Magalhães Drummond, Edição Revista Forense, Rio, 1944, vol. IX, pg. 289. 
Pergunta - $\left.1 .^{\circ}\right)$ Qual a distinção entre mandado de segurança normativo e preventivo ou repressivo, em relação aos efeitos temporais da ordem concedida?

Resposta - $\left.1 .^{\circ}\right)$ Mandado de Segurança normativo seria ato equiparável à da tipificação genérica da lei com aplicabilidade aos casos futuros, eventuais ou não determinados. Este tipo de provimento não existe em nosso sistema judiciário.

A ordem concessiva do mandado de segurança preventivo opera "ex nunc", em relação aos casos futuros e determinados na lide.

A ordem do mandado de segurança repressivo opera "ex tunc" em relação ao caso da lide e, passando em julgado, aos casos futuros e determinados na lide.

Pergunta - 2..$^{\circ}$ A decisão de mérito, proferida “in casu", no mandado de segurança concedido definitivamente à ora consulente, é oponível à autoridade coatora, como ordem para cessar ou não repetir essa mesma coaçẫo, ou teria a vítima da coação de assoberbar o Poder Judiciário com a impetração de mandados de segurança em relação a cada um dos inumeráveis atos praticados e continuados, de saída dos caminhões ou de emissão de cada nota fiscal?

Resposta - 2. ) A decisão de mérito proferida no mandado de segurança "in casu" e concedida definitivamente à consuJente foi de uma ordem para cessar a coação, consistente esta na pretensão de a Fazenda do Estado exigir ICM, cuja pretensa causa somente poderia ser a existência de determinada relação jurídico-tributária. Tendo o Poder Judiciário julgado inexistente essa relação, a ordem é permanente enquanto não alterado o substractum nem superveniente lei criadora de tal relação juridica entre a Concretex e a Fazenda do Estado de São Paulo.

Pergunta - $3^{\circ}$ ) A decisão de mérito sobre a relação jurídico-tributária "in casu”, no Mandado de Segurança, constitui "coisa julgada"? 
Resposta - 3..$^{\circ}$ Sim.

Pergunta - $4^{\circ}$ ) A decisão de mérito sobre a relação jurídico-tributária "in casu", na ação executiva fiscal, constitui "coisa julgada"?

Resposta - 4..$^{\circ}$ Sim.

Pergunta - 5..$^{\circ}$ Por se tratar de impostos não pode o contribuinte obter do Poder Judiciário a segurança e tranquilidade quanto a uma determinada relação jurídico-tributária contínua?

Resposta - 5..$^{\circ}$ Pode, como de fato e de direito ocorreu no caso consultado. 